\title{
Acerca da Taxonomia do Mental para Contextos que REQUEREM NEUTRALIDADE
}

\author{
FILIPE LAZZERI \\ Universidade de São Paulo
}

\begin{abstract}
Ordinary psychological (or mental) predicates, and the phenomena we report to by means of them, can be grouped together into different categories. For instance, it is usual to group together phenomena such as belief and expectancy in a category of 'propositional attitudes', whereas sensations, like pain and itch, in a distinct one. Which taxonomy of the mental would be plausible to be adopted in contexts such as those of introductory books to the philosophy of mind, i.e., when we need to set out only from minimal assumptions regarding these predicates and phenomena? This article (1) suggests some desiderata and principles for such a taxonomy; (2) exposes and critically assesses some taxonomies presented in introductory books to the philosophy of mind; and (3) proposes the sketch of an alternative one (for the same kind of context).
\end{abstract}

Keywords: Psychological categories; taxonomy of the mental; philosophy of mind.

Os predicados psicológicos (ou mentais) ordinários (e.g., ‘... crer que... ’, ‘... tencionar...', '... estar aflito com...', '... ouvir...') e os fenômenos aos quais nos remetemos através desses predicados (e.g., o ter uma expectativa, o almejar, o ter medo) podem ser agrupados em diferentes categorias. Por exemplo, costuma-se agrupar fenômenos como os de crença e expectativa em uma categoria de "atitudes proposicionais", enquanto que sensações, como as de dor e coceira, em uma categoria distinta. Através de agrupamentos desses predicados ou fenômenos, forma-se uma taxonomia do mental (de caráter semântico, no primeiro caso, ao passo que metafísico ou ôntico, no segundo). Qual seria uma plausível para se adotar em contextos como o de um livro de introdução de filosofia da mente, ou seja, quando se deseja partir de pressupostos apenas mínimos sobre as características desses predicados e fenômenos? ${ }^{1}$

Este trabalho (1) sugere alguns desideratos e princípios para uma taxonomia relativa ao referido tipo de contexto; (2) expõe e examina criticamente algumas taxonomias do mental feitas em livros de introdução à filosofia da mente, em particular as de Maslin (2001), McGinn (1996) e Rey (1997); e (3) sugere o esboço de uma taxonomia alternativa (para o mesmo tipo de contexto). O trabalho está estruturado em três seções gerais, uma para cada um desses objetivos.

Por taxonomia, entendemos, aqui, uma classificação que possui pelo menos três aspectos inter-relacionados: (i) um aspecto estrutural, correspondente às ramifica-

Principia 16(3): 365-392 (2012).

Published by NEL — Epistemology and Logic Research Group, Federal University of Santa Catarina (UFSC), Brazil. 
ções das categorias distinguidas; (ii) um aspecto terminológico, correspondente às terminologias adotadas para essas categorias; e (iii) um aspecto intensional, correspondente às características que as delimitam.

\section{Desideratos e princípios para uma taxonomia do mental em contextos que requerem neutralidade}

Uma taxonomia do mental (seja ela semântica ou ôntica) é relativa a algum propósito, isto é, ela depende do contexto em que se enquadra. Portanto, a pergunta por uma taxonomia plausível do mental depende do tipo de contexto que esteja em questão. Os desideratos que se espera que ela cumpra variam conforme o propósito que possua. A seguir, antes de sugerirmos os desideratos e princípios para uma taxonomia do mental, fazemos uma delimitação do tipo de contexto que está em foco neste trabalho.

\section{Dois Contextos de Taxonomias do Mental}

Há pelo menos dois tipos de contextos de taxonomias do mental. Um deles é o de abordagens ou teorias específicas do mental, sejam elas em filosofia da mente, psicologia ou ainda outra área. Nesses contextos - os quais, doravante, chamamos de contextos (T) - as características dos predicados ou fenômenos mentais já estão modeladas pela abordagem, contrapondo-se a abordagens (concorrentes) que as modelam de um modo por ela considerado insatisfatório. Ou seja, em contextos (T), esses predicados ou fenômenos são classificados consoante respostas que a teoria específica propõe a questões substanciais a seu respeito; por exemplo, sobre se as reações frequentemente associadas a emoções (como as reações de aumento do batimento cardíaco, enrubescimento e empalidecimento da pele, tremores no corpo, etc.) são apenas efeitos das emoções ou, antes, elementos constitutivos delas; sobre se certos fenômenos mentais individuam-se de modo internista ou externista; etc.

Outro tipo de contexto de taxonomias do mental é o daqueles em que se requer neutralidade quanto às questões substanciais acerca dos predicados ou fenômenos mentais. Esses contextos - os quais, doravante, chamamos de contextos (RN) são aqueles em que se deseja partir de pressupostos apenas mínimos (ou seja, manter grande neutralidade) sobre esses itens. É o tipo de contexto exemplificado, por exemplo, por vários livros e cursos de introdução à filosofia da mente (sobretudo naqueles que pretendem apresentar algumas questões e abordagens tradicionais ao leitor ou uma visão geral da área), quando não se deve de antemão pressupor respostas às questões centrais, nomeadamente, relativas à melhor maneira de caracterizar os referidos itens (sob pena, por exemplo, de cometer petições de princípio ou 
apresentar de maneira enviesada as abordagens de interesse) ${ }^{2}$. Vários livros de introdução à filosofia da mente (e.g., Kim 1996; Maslin 2001; McGinn 1996; Rey 1997) partem explicitamente de alguma taxonomia dos referidos predicados ou fenômenos - embora, por vezes, sem pretensão de que seja uma completa —, ou assumem implicitamente alguma (e.g., Churchland 1988; Heil 2004; Braddon-Mitchel \& Jackson 2007).

No presente trabalho, estão em foco apenas os contextos (RN). Ou seja, a pergunta que aqui nos concerne não é uma pergunta simplesmente sem mais sobre qual seria uma taxonomia plausível do mental; antes, trata-se da pergunta sobre qual seria uma plausível para se adotar em um contexto em que é adequado partir de pressupostos apenas mínimos sobre as características dos predicados ou fenômenos mentais.

\section{Três Desideratos e Princípios}

Sugerimos três desideratos (condições que se espera que sejam satisfeitas) e princípios (regras correspondentes para se satisfazer esses desideratos) para uma taxonomia voltada a contextos (RN). São os seguintes: (a) ser abrangente/princípio da abrangência; (b) ser neutra/princípio da neutralidade; e (c) não ser demasiado pouco taxonômica/princípio da arregimentação. A seguir, esses desideratos e princípios são caracterizados.

(a) Ser abrangente/princípio da abrangência: abranger o maior número possível (isto é, todas as formas) de conceitos ou fenômenos consensualmente mentais (ou psicológicos) ${ }^{3}$ na taxonomia. Isso porque, em primeiro lugar, uma abordagem geral de filosofia da mente requer consideração das diferentes formas do mental: é seu intuito essa abrangência. No caso de uma abordagem restringida a um subconjunto do mental, isso é potencialmente útil para estabelecer a distinção entre tal conjunto e os conjuntos de que não pretende tratar. Em segundo lugar, levar em conta o maior número possível de conceitos ou fenômenos consensualmente mentais é útil para evitar um viés a exemplos de apenas uma ou poucas categorias, em detrimento de outras. Evitar tal viés é importante ao se avaliar uma abordagem, já que ela pode ser plausível para algumas categorias, mas implausível para outras; e também ao se desenvolver uma abordagem, já que, de modo a ser razoável, ela deve preservar possíveis especificidades de cada categoria. Conforme apontamos na seção 2, algumas taxonomias feitas em contextos (RN) não levam em conta certas formas do mental, assim deixando a desejar quanto à abrangência.

A qualificação 'consensualmente', aqui, visa viabilizar que haja, de fato, uma taxonomia. Por um lado, se a taxonomia é do mental, então apenas predicados ou fenômenos mentais devem ser considerados nela. Por outro lado, sabemos que predicados ou atributos que não são geralmente reputados como mentais (e.g., dispo- 
sições como a de solubilidade em água possuída por certas substâncias) podem ser teorizados como na verdade o sendo (como ocorre, por exemplo, em perspectivas pampsiquistas). Assim, se queremos uma taxonomia para contextos (RN), convém o meio termo de nela abranger todos os predicados ou atributos apenas consensualmente vistos como tais (e.g., emoções e fenômenos perceptuais), deixando em aberto, entretanto, a possibilidade de haver categorias mentais que comumente não consideramos como tais.

(b) Ser neutra/princípio da neutralidade: ser uma taxonomia o mais neutra possível, isto é, evitar posicionamentos de antemão sobre questões controversas acerca dos conceitos ou fenômenos em pauta. Esta neutralidade não pode ser inteira, ou seja, a distinção entre neutralidade e parcialidade é apenas de grau; pois classificar implica em delimitar pelo menos algumas características gerais do que está sendo classificado. A taxonomia tem maior ou menor neutralidade conforme a posição que ocupa em um espectro que mensura quanto ela envolve posicionamentos sobre tais questões. Por exemplo, uma taxonomia (no caso, semântica) que assuma que os predicados relativos ao perceber (e.g., '... ver...', '... ouvir...') sejam da mesma categoria daqueles relativos ao ter sensações (e.g., ‘... ter dor em...', ‘. . ter uma coceira em...') é menos neutra a respeito desses predicados do que uma classificação em que eles não são encaixados de início em uma mesma categoria, já que há bastante controvérsia quanto a se os primeiros são suficientemente semelhantes aos segundos (cf., e.g., Armstrong 1984, p.169ss; Ryle 1949, p.199ss; Bennett \& Hacker 2003, p.121ss). Estar em consonância com o princípio da neutralidade é um desiderato porque, em primeiro lugar, o tipo de contexto aqui em pauta demanda isso, ou seja, trata-se de contextos em que não se deve pressupor respostas aos principais subproblemas envolvidos na problemática geral (a saber, sobre a melhor ou sobre uma razoável modelagem dos conceitos ou fenômenos mentais). Em segundo lugar, isso potencialmente ajuda a evitar petições de princípio ao se examinar uma proposta específica de modelagem de formas do mental. ${ }^{4}$ Como mostramos na seção 2 , muitos livros introdutórios à filosofia da mente partem de taxonomias que assumem respostas controversas de antemão acerca de subproblemas envolvidos na problemática geral à qual pretendem introduzir o leitor, assim deixando a desejar quanto à neutralidade.

(c) Ser suficientemente taxonômica/princípio da arregimentação: fazer agrupamentos minimamente consensuais dos conceitos ou fenômenos mentais. Do contrário, não se oferece, em última instância, uma taxonomia como um ponto de partida (mas apenas uma lista de exemplos do mental), quando isso não é o que se espera, já que há acordo em que alguns deles compartilham características importantes que outros deles não. Ou então mistura-se elementos em uma categoria sem subdividi-la, quando, antes, por mais que a categorização possa ser correta (nomeadamente, por os elementos possuírem características gerais comuns), essas diferenças requerem 
atenção através de um encaixamento deles em pelo menos subcategorias (sob pena, inter alia, de avaliar-se uma abordagem demasiado apressadamente). Por exemplo, por mais que sensações e emoções sejam atributos que possam ser encaixados em uma mesma categoria geral, porquanto compartilham feições como as de estarem (conceitualmente) ligados a inferências da forma '... sente...' ou '... sente-se...', diferem significativamente em as sensações terem (pelo menos geralmente) alguma forma de localização explícita no corpo (e.g., dizemos que elas estão no pé, na cabeça, etc.) ${ }^{5}$ ao passo que as emoções não. ${ }^{6}$ A consonância com o princípio da arregimentação permite calibrar o princípio da neutralidade: por um lado, a taxonomia deve ser neutra, mas, por outro, não convém deixar de levar em conta as nuanças de entendimento (a respeito das quais geralmente há acordo) dos conceitos ou fenômenos em pauta.

A experiência com a prática filosófica ensina que poucas questões, se é que alguma, em filosofia, são de muito grande consenso; mas isso ocorre principalmente com as questões substanciais. Costuma-se haver, pelo menos implicitamente, um acordo mínimo sobre questões de entendimento acerca do que se está falando, sob pena de não se saber o que diz ou de não ser possível o diálogo. É minimamente consensual, por exemplo, que ter uma opinião e saber jogar xadrez são atributos que possuem um caráter disposicional (ou ainda, não episódico) (isto é, que alguém pode ter uma opinião ou saber jogar xadrez mesmo quando está dormindo; não se trata de fenômenos que ocorram sincronicamente; não faz sentido dizer que alguém esteja crendo ou sabendo jogar xadrez em um momento particular), ao passo que sentir uma coceira e enxergar um objeto são acontecimentos episódicos (os quais podem ocorrer sincronicamente; dão-se em momentos particulares), de tal modo que podemos classificar os primeiros em categorias (ao menos subcategorias) diferentes dos últimos. Cada um dos conceitos ou fenômenos mentais, em geral, têm características específicas, mas é consensual que também apresentam, ou pelo menos tendem a apresentar, características comuns, sendo assim agrupáveis em categorias.

Essas categorias não precisam necessariamente ser entendidas como conjuntos no sentido da teoria clássica dos conjuntos. Elas podem ser consideradas como categorias difusas, isto é, as características relevantes de seus elementos podem revelarse, eventualmente, ser apenas similaridades de família (cf. Wittgenstein 1953), no sentido de os elementos tenderem a exibi-las, mas não as exibirem sempre, sem que por isso deixem de pertencer ao conjunto, tal como no caso dos diferentes elementos que classificamos como jogos e daqueles que classificamos como cadeiras.

Segundo um holismo como o de Quine (1961), qualquer nuança básica associada a algum predicado ou atributo resulta ser, em última instância, revisável. Logo, se tal holismo estiver correto, adotar o princípio da arregimentação não tem por implicação que as nuanças que ele recomenda capturar sejam imunes a revisões. Nada impede, em princípio, que uma teoria considere errônea uma ou mais nuanças de 
um conceito ou fenômeno mental. No entanto, os contextos adequados para eventuais revisões nessas nuanças (revisões que podem revelar-se razoáveis ou não) são os contextos (T), e não os contextos (RN).

\section{Algumas Taxonomias em Contextos (RN)}

Munidos dessas distinções, passamos, agora, a expor e a avaliar algumas taxonomias feitas em contextos (RN); em particular, as de McGinn (1996), Rey (1997) e Maslin (2001), nesta ordem de autores.

\section{A Taxonomia de McGinn (1996)}

Esta taxonomia é ôntica e tem a seguinte estrutura:

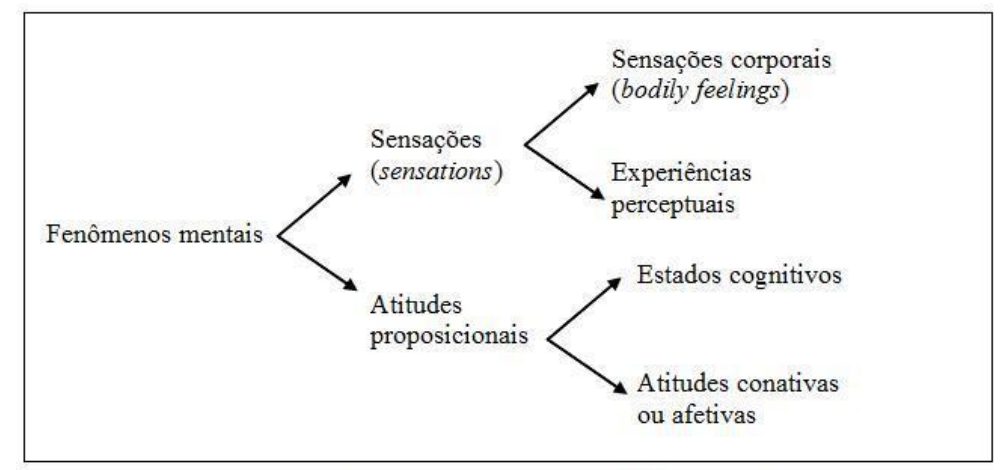

Figura 1: Estrutura da taxonomia de McGinn (1996)

McGinn (1996, p.8-10) classifica os fenômenos mentais em duas categorias básicas: sensações e atitudes proposicionais. As sensações, segundo esta taxonomia, são de dois tipos: sensações corporais, como, por exemplo, dores, coceiras e náuseas; e experiências perceptuais, como, por exemplo, o ver, o ouvir e o cheirar. ${ }^{7}$ O que é comum a ambos os tipos de sensações, segundo McGinn, é: (a) serem definidas pela sua fenomenologia, isto é, pela maneira como aparecem ao sujeito que os exemplifica (e.g., o cheirar uma fruta ser definido por aquilo que se experimenta subjetivamente ao cheirá-la) - por como é estar (what it is like to be) nelas, nos termos de Nagel (1974), ou ainda, em outros termos, pelos seus conteúdos qualitativos ou qualia —; (b) sua posse por um sujeito não ser suficiente para qualificá-lo como ser racional, no sentido de ser que raciocina e que age conforme razões; e, além disso, (c) serem fenômenos intrinsecamente conscientes (por oposição a poderem ser inconscientes), no sentido de que, quando um sujeito os exemplifica, ipso facto nota uma mudança correspondente (não fazendo sentido se dizer, por exemplo, que alguém tenha uma cócega, mas não a note). O que distingue os dois tipos de sensações, consoante McGinn, é as sensações corporais não envolverem a propriedade de intencionalidade 
ou conteúdo intencional (ou proposicional), a qual, segundo o autor, é exibida pelos fenômenos cujas atribuições envolvem complementos frasais da forma 'que...' (thatclauses), ao passo que as experiências perceptuais sim. Em outras palavras, conforme o autor, sensações corporais, diferentemente das percepções, não são relações com estados de coisas possíveis ou efetivos.

As atitudes proposicionais são subdivididas, nesta taxonomia, em dois tipos: cognitivas, como, por exemplo, crenças; e conativas (ou afetivas), como, por exemplo, desejos e intenções. O que é comum às diferentes atitudes proposicionais, segundo McGinn, é: (a) serem relações entre agentes e conteúdos intencionais (ou proposicionais), no sentido de as atribuições desses fenômenos envolverem complementos frasais da forma 'que... ', os quais expressam proposições (ou condições de verdade); (b) envolverem normatividade, no sentido de as atribuições delas alicerçarem-se em suposições sobre quais o sujeito dessas atribuições deve ter (ought to have), em um sentido normativo (e não meramente probabilístico), dadas outras atitudes proposicionais que se suponha que ele exemplifique (cf. também McGinn 1996, p.20-22); (c) poderem ser inconscientes (no sentido de poderem não ser notadas por quem as exemplifica); e (d) não se definirem por alguma fenomenologia, isto é, sua fenomenologia, se alguma, é apenas incidental (e.g., por mais que ocorram, eventualmente, conteúdos qualitativos quando alguém declara uma opinião, esses conteúdos são incidentais à posse da opinião).

A taxonomia de McGinn (1996) não pressupõe que cada fenômeno mental se defina ou por um conteúdo qualitativo ou por um conteúdo intencional. Pois admite que as experiências perceptuais exibem tanto conteúdo qualitativo como conteúdo intencional relevantes: são, segundo o autor, identificáveis por ambos os tipos de propriedades.

\section{Ponderações à Taxonomia de McGinn (1996)}

Há, a nosso ver, vários problemas na taxonomia de McGinn (1996). Nas ponderações (i)-(iv) seguintes, sugerimos que ela deixa a desejar quanto à abrangência.

(i) A taxonomia em pauta não inclui várias formas de afecções; nomeadamente, emoções (e.g., ter medo, raiva, vergonha, admiração), humores (moods) (e.g., estar entusiasmado, alegre, triste, melancólico) e apetites (e.g., estar com fome, sede, concupiscência). Logo, ela não satisfaz o desiderato da abrangência. Emoções, humores e apetites não satisfazem o conjunto de critérios do autor para nenhuma das categorias que distingue. Não satisfazem aquele que o autor associa às atitudes proposicionais porquanto, por exemplo, apenas alguns (particulares) daqueles fenômenos (nomeadamente, apenas emoções e em certos casos, como o ter medo de que algo aconteça) são atribuíveis em predicações constituídas por complementos frasais da forma 'que...'; humores e apetites em geral não o são; e tampouco emoções 
em certos casos, como o aprazer-se com algo ou alguém (ou seja, o critério (a) do autor para atitudes proposicionais não é satisfeito). Além disso, sua posse por um sujeito, evidentemente, não depende de ele ser racional, no sentido do autor (ter medo, fome, sede, etc. são fenômenos que inclusive encontramos praticamente em todo, senão em todo, o reino animal) (ou seja, o critério (c) do autor para atitudes proposicionais não é satisfeito). Já se o autor encaixasse emoções, humores e apetites em sua categoria de sensações, falharia quanto ao desiderato da neutralidade; por exemplo, no que tange ao critério (a) para sensações. Pois está longe de ser claro que alguns casos dessas afecções, como as de ter prazer com uma partida de xadrez, admirar alguém pela sua virtuosidade, ter satisfação com a leitura de determinado texto, estar tranquilo, etc., envolvam conteúdos qualitativos necessariamente (cf., e.g., Bennett \& Hacker 2003, p.203-5). É também disputável, de modo mais geral, se emoções, humores e apetites realmente têm uma fenomenologia constitutiva (por oposição a meramente incidental). Arguivelmente, para que um organismo tenha, por exemplo, fome, não é fundamental que nele esteja ocorrendo alguma experiência fenomênica. De acordo com pelo menos algumas perspectivas comportamentais (e.g., Rachlin 1994), o relevante é que o organismo exiba comportamentos de forrageamento ou apresente certas reações que favoreçam a obtenção de alimento que aprecia, em circunstâncias relevantes (como a proximidade de lugares em que tipicamente há alimento). Conforme perspectivas funcionalistas mais difundidas (e.g., Lewis 1972; Putnam 1975a, 1975b), o relevante é que comportamentos como esses, nas circunstâncias relevantes, sejam causados por entidades internas que tenham um papel causal supostamente associado à fome.

(ii) A taxonomia de McGinn (1996) não está em consonância com o desiderato da abrangência também por deixar de lado boa parte dos fenômenos por vezes chamados de processos cognitivos (alguns dos quais são mais propriamente cogitativos), como aqueles relativos ao pensar (no sentido de processo, e não de crença) (e.g., raciocinar, refletir, calcular), à memória (e.g., recordar, memorizar) e ao imaginar. (Dos fenômenos em questão, apenas os perceptuais são distinguidos pelo autor em sua taxonomia.)

Em determinado momento do livro (a saber, nos capítulos 6 e 7), McGinn (1996, p.83ss) menciona alguns desses fenômenos, apesar de não tê-lo feito em sua taxonomia (presente no capítulo 1 do livro). Porém, não é claro em que categoria, se em alguma, de sua taxonomia o autor os encaixaria. Se os encaixasse na categoria de sensações, então cometeria um problema terminológico, sintomático de uma falha quanto ao desiderato da neutralidade, porquanto não faz sentido chamar o raciocinar, o recordar, o imaginar, etc. de sensações. Se, por outro lado, encaixasse esses fenômenos na categoria de atitudes proposicionais, então a subsunção seria também problemática, porquanto eles, em geral, são ocorrências, isto é, têm um caráter episódico (pois, por exemplo, faz sentido dizer-se que alguém esteja calculando ou 
imaginando algo de baixo de uma árvore, em um momento particular), ao passo que atitudes proposicionais têm um caráter disposicional (pois, por exemplo, não faz sentido se dizer que alguém esteja tendo uma opinião de baixo de uma árvore, em um momento particular). ${ }^{8}$

(iii) Outros atributos que estão ausentes na taxonomia em pauta - assim novamente deixando a desejar quanto ao desiderato da abrangência - são os traços de caráter ou de personalidade, como, por exemplo, os de ser honesto, sagaz, inteligente, vaidoso, raivoso, extrovertido, introvertido, etc. Há quem os considere analisáveis em termos de fenômenos mentais agrupáveis em outras categorias, tomadas como mais básicas (e.g., Brandt 1970; Kim 1996, p.15). Isso pode, eventualmente, ser uma tese correta, mas, em qualquer caso, esses atributos não devem ser negligenciados em uma taxonomia do mental em contextos (RN), conforme o desiderato da abrangência.

(iv) A classificação de McGinn (1996) também deixa de lado as habilidades, como, por exemplo, as de saber preparar uma comida (e.g., arroz), jogar um jogo ou esporte (e.g., xadrez), falar uma língua (e.g., português), tocar um instrumento musical (e.g., piano), desenhar, etc., também chamadas de formas de saber como (know-how). Habilidades não satisfazem os critérios do autor quer para sensações posto que, por exemplo, não são intrinsecamente conscientes - , quer para atitudes proposicionais - já que, por exemplo, não são atribuídas na forma de predicações constituídas por complementos frasais da forma 'que...'.

As objeções (v)-(vii) a seguir não implicam em uma problematização da estrutura da taxonomia de McGinn; pelo menos não o fazem sem o acréscimo de outras premissas. Entretanto, (v)-(vii) são, como as ponderações anteriores, instrutivas para a delimitação de uma taxonomia mais adequada do mental, para os contextos (RN) (uma taxonomia tendo outras dimensões, também importantes, além da estrutural).

(v) Há um problema com a adoção da terminologia de 'sensações' (sensations) para englobar tanto as sensações corporais como as experiências perceptuais. Pois está longe de ser claro que experiências perceptuais sejam sensações, mesmo em um sentido amplo do termo. Ele conota, em geral, atributos que têm alguma forma de localização explícita no corpo (e.g., em braços, pernas, cabeça), ou que pelo menos estão (conceitualmente) associados a inferências da forma '. . . sente. . .'. No entanto, nem todas as experiências perceptuais apresentam essas propriedades. Experienciamse perceptualmente objetos que têm localização em algum lugar, mas os objetos da experiência perceptual, segundo vários autores (e.g., Armstrong 1984, p.169ss; Austin 1962; Harman 1990; Sartwell 1995), têm localização tão somente no ambiente maior, e não no interior do corpo (ou seja, o perceber não é indireto ou mediado); por exemplo, segundo eles, ao se ver um prato sobre a mesa, tem-se uma experiência apenas do que está lá sobre a mesa; ao se ouvir o latido um cão, tem-se a experiência apenas do que está ocorrendo no ambiente onde o cão emite esse comportamento; 
quando se toca uma maçã com a mão direita, o que se sente é apenas o que está na mão. Além disso, é dúbio que todas as experiências perceptuais estejam ligadas (conceitualmente) a inferências da forma '... sente...'. Aquelas relacionadas ao paladar, ao tato e ao olfato o estão (e.g., quando se cheira e se toca uma maçã, sente-se seu odor e seu peso ou solidez, respectivamente), mas não é claro se aquelas relacionadas à visão e à audição também (e.g., que, ao se enxergar o céu, se esteja ipso facto sentindo o céu; quando se ouve o latido de um cão, se esteja ipso facto sentindo esse latido). Logo, pelo princípio da neutralidade, é recomendável não incluir a categoria das experiências perceptuais em uma categoria de sensações, em contextos (RN).

(vi) Embora, na filosofia contemporânea, seja frequente a suposição de que as "atitudes proposicionais" sejam relações entre agentes e conteúdos proposicionais - como indicado pela própria terminologia que (a partir de Russell) se estabeleceu -, não se trata de uma suposição sem questionamentos (o que não é surpresa, sendo uma questão substancial). A ideia mesma de proposição é objeto de reticência por parte de alguns autores, como Quine (1960), que considera os critérios de identidade das reputadas entidades abstratas denotadas por tal ideia serem obscuros. Além disso, algumas perspectivas sobre atitudes proposicionais (e.g., Davidson 2001; Dennett 1987; Ryle 1949) não as caracterizam em termos dessa suposição. Assim, pelo desiderato da neutralidade, é recomendável não caracterizar esses fenômenos como relações entre agentes e conteúdos proposicionais, em contextos (RN).

(vii) A caracterização da noção de intencionalidade em termos de ser uma propriedade designada por atribuições compostas por complementos frasais da forma 'que...' pode ser demasiado restritiva. Pois, embora haja desejos de que algo ocorra ou não, há também desejos de obtenção de algo $X$ ou de realização de uma atividade A. Isso ocorre similarmente com outras atitudes proposicionais, além de com as experiências perceptuais: pode-se ter intenção de que algo seja ou não o caso, mas por vezes tencionamos $a$ obtenção de algo ou fazer algo; pode-se esperar que algo ocorra ou não, mas também se esperar por algo; pode-se ver que há certo objeto em determinado local, mas também ver um (ou o) objeto; e assim por diante. Prima facie, não é claro se é fidedigno reduzir essas atribuições a atribuições constituídas pelo complemento frasal 'que...' P. Pois, no caso da redução de algumas dessas atribuições, muda-se o objeto envolvido no fenômeno; por exemplo, na atribuição de um desejo de obter $X$ ou de fazer $A$, dir-se-ia então que um sujeito $s$ deseja que $s$ obtenha $X$ ou que $s$ deseja que $s$ faça $A$, de modo que o objeto do desejo passaria a incluir $s$, e, assim, a ser outro que, propriamente, $X$ e $A$ (para considerações similares, cf. Glock 2001, p.107-8; Montague 2007).

(viii) Como corolário de (vii), pode-se levantar ainda outra ponderação que, como (i)-(iv), tem implicação para a estrutura da taxonomia de McGinn (1996); a saber, a ponderação de que é disputável se sensações corporais não têm intencionalidade. Há abordagens (e.g., Armstrong 1968; Harman 1990; Tye 1995) que 
sugerem que as sensações corporais exibem essa propriedade. Assim, pelo desiderato da neutralidade, é recomendável deixar em aberto se elas têm-na ou não. Se esta ponderação estiver correta, então a subdivisão de McGinn de sua categoria de sensações em sensações corporais e experiências perceptuais não se mantém (salvo adicionando-se algum critério diferente para tanto, o que pode, eventualmente, ser plausível). Pois o parâmetro adotado pelo autor para essa subdivisão (como salientamos) é de sensações corporais não exibirem intencionalidade. O autor tem como premissa para sua exclusão da possibilidade de sensações corporais terem intencionalidade a ideia de que as atribuições delas não envolvem complementos frasais da forma 'que...', premissa questionada em (vii). ${ }^{9}$

\section{A Taxonomia de Rey (1997)}

Esta taxonomia é apresentada em termos ônticos, mas pretende admitir, simultaneamente, uma interpretação semântica (cf. Rey 1997, p.14, p.30). É semelhante à de McGinn (1996), subdividindo o mental em duas grandes categorias, inclusive similares àquelas apontadas por esse autor. No entanto, tais taxonomias diferem um pouco em terminologia, bem como em alguns pormenores na caracterização dessas categorias, além de em aquela de Rey não subdividir (em subcategorias) uma delas. Sua estrutura pode ser representada como se segue:

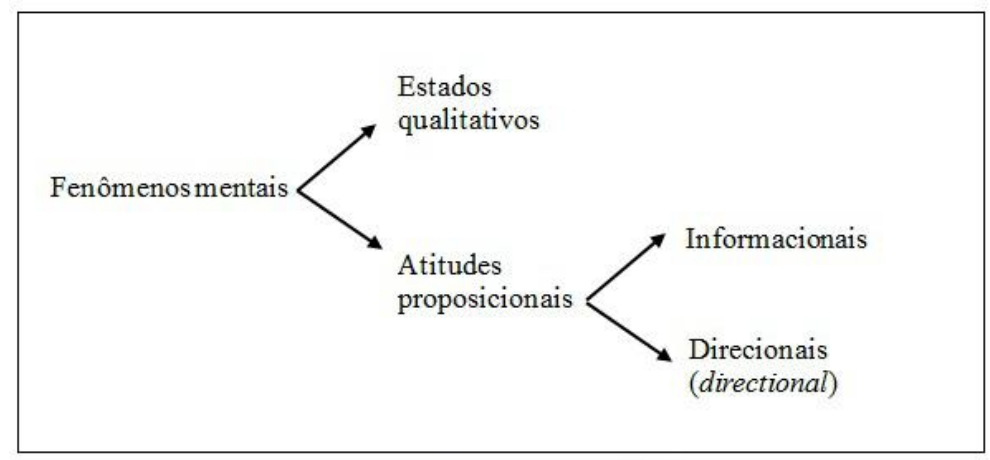

Figura 2: Estrutura da taxonomia de Rey (1997)

Segundo a taxonomia de Rey (1997, p.18-20), os fenômenos mentais subdividem-se em estados qualitativos e atitudes proposicionais. Exemplos de estados qualitativos são: ter sensações de dor, cócega, coceira; ver, ouvir, cheirar; imaginar, lembrar. Os estados qualitativos são fenômenos (a) dos quais parecemos estar imediatamente conscientes; e (b) que estão frequentemente associados com algum sentimento ou impressão (a expressão utilizada por Rey é o substantivo feel) particular, como, por exemplo, impressões de dor, cócega, cor, som, sabor, imagem (no imaginar) e lembrança (no lembrar) (cf. também Rey 1997, p.327), ou seja, eles 
possuem uma dimensão fenomenológica relevante (há algo como o estar no estado, como coloca Nagel 1974).

As atitudes proposicionais, segundo Rey, são de dois tipos: informacionais e direcionais. De acordo com o autor, as informacionais representam o mundo como sendo de determinado jeito ao invés de outro (isto é, representam determinados estados de coisas como sendo ou não o caso); por exemplo, o achar que há maçãs na mesa da cozinha. As direcionais motivam o agente com relação a um modo particular como o mundo pode estar; por exemplo, o desejar comer uma maçã. Essas subcategorias não são exclusivas, podendo uma atitude proposicional ser ao mesmo tempo informacional e direcional; por exemplo, o gostar do fato de haver maçãs na cozinha. O que é comum às atitudes proposicionais das diferentes subcategorias, consoante esta taxonomia, é (a) serem estados designados por verbos que têm como objetos diretos complementos da forma 'que...' ou 'de...', os quais podem ser entendidos como partes não referenciais daqueles verbos - no caso, tomados como predicados monádicos (e.g., '... ter a expectativa de finalizar a escrita de um livro neste ano', '... achar que o dia será muito agradável') (como sugere Quine 1960) —; ou, antes, como proposições (ou conteúdos proposicionais) com as quais o sujeito se relaciona — no caso, os verbos sendo tomados como predicados diádicos (e.g., '... ter a expectativa de...', '... achar que...'). Em qualquer caso, geram-se contextos opacos, isto é, que não satisfazem a lei de substituição de idênticos de Leibniz. ${ }^{10}$ Pelo menos no segundo caso, diz-se que o fenômeno exibe intencionalidade. Além disso, as atitudes proposicionais, segundo esta classificação, (b) exibem potencial racionalidade (isto é, podem ser racionais), o que o autor associa à propriedade de haver coerência de uma com outras exemplificadas pelo sujeito e, em alguns casos, com evidências (e.g., a crença de que vai chover é potencialmente racional, de fato o sendo quando há indícios em apoio de que vai chover; querer fazer algo pode ser racional, frequentemente o sendo quando se deseja obter certo resultado e não haver certa incompatibilidade com isso); (c) podem ser inconscientes, no sentido de um sujeito não necessariamente saber que as exemplifica; e, por fim, (d) não apresentam uma dimensão fenomenológica constitutiva.

\section{Ponderações à Taxonomia de Rey (1997)}

A taxonomia ora exposta é mais neutra do que a de McGinn (1996). Isso ocorre, dentre outras razões, por manifestar que as atitudes proposicionais não necessariamente são designadas por atribuições envolvendo complementos frasais da forma 'que...', podendo o serem da forma 'de...'; e salientar que são interpretáveis (deixando em aberto, claro, se plausivelmente ou não) como não sendo relações com proposições em sentido estrito. Entretanto, a taxonomia de Rey (1997) também requer várias ponderações (várias delas semelhantes a (i)-(iv) à de McGinn). Não é claro se Rey 
a estabelece procurando generalidade, ao invés de procurando apenas mencionar categorias que considera mais centrais. Se o faz com apenas este segundo intuito, algumas das ponderações a seguir não são exatamente objeções, mas pelo menos servem para visualizarmos limitações importantes dessa taxonomia.

(i) Esta taxonomia ou oblitera humores e apetites, assim falhando quanto ao desiderato da abrangência, ou, se (implicitamente) os inclui, falha quanto ao desiderato da neutralidade. Em nenhum momento Rey (1997) menciona, em sua taxonomia, humores (e.g., estar alegre, melancólico) e apetites (e.g., estar com fome, sede) como exemplos das categorias que distingue. De fato, tais fenômenos não satisfazem o conjunto de critérios do autor para atitudes proposicionais; pois, por exemplo, não se trata de fenômenos atribuídos em predicações constituídas de complementos frasais da forma 'que...' ou 'de...'. Além disso, arguivelmente, tampouco satisfazem os critérios do autor para a categoria de estados qualitativos; pois está longe de ser claro que humores e apetites são, e mesmo aparentem ser, de imediata consciência ao sujeito que os exemplifica. Esses (tipos de) atributos têm caráter disposicional (e.g., pode-se estar em um humor durante dias), assim não se tratando de algo do que possamos dizer que haja imediata consciência. Logo, pelo desiderato da neutralidade, é recomendável não alocar esses fenômenos na categoria de estados qualitativos (ao menos tal como caracterizada pelo autor).

(ii) Rey (1997) praticamente deixa de lado as emoções em sua taxonomia, assim falhando quanto ao desiderato da abrangência; ou, se (implicitamente) as considera, o faz de maneira problemática quanto ao desiderato da neutralidade. Emoções não são distinguidas nessa classificação como uma categoria (ou subcategoria), mas o autor menciona o odiar (que é uma emoção) como exemplo de atitude proposicional direcional. Assim, o autor provavelmente inclui outras emoções em tal subcategoria de atitudes proposicionais. No entanto, em primeiro lugar, há emoções que atribuímos sem os complementos frasais tomados pelo autor como típicos das atitudes proposicionais (ou seja, nem toda emoção satisfaz o critério (a) do autor para tal categoria). É o caso de fenômenos como os de estar contente, aprazer-se e comover-se; dizemos geralmente que um organismo está contente, aprazer-se ou comove-se com algo. Em segundo lugar, não é consensual que as emoções em geral satisfaçam os critérios (b) e (d) do autor para atitudes proposicionais, isto é, que sejam potencialmente racionais e que não tenham fenomenologia constitutiva. Pois, como se sabe, considera-se, na tradição filosófica moderna, que emoções não são atributos racionais (apesar de haver razões em contrário) (cf. de Sousa 1994, p.275-6; Solomon 1977). Ademais, há autores (e.g., Chalmers 1995; Maslin 2001, p.11-2; Tye 1995) que consideram emoções como casos de fenômenos que exibem, em alguma medida (alguns sugerem que apenas quando sentidas), fenomenologia constitutiva. Logo, pelo princípio da neutralidade, não convém uma subsunção das emoções à categoria de atitudes proposicionais (pelo menos tal como caracterizada pelo autor). 
(iii) Não é claro em que categoria Rey (1997) aloca, se em alguma, fenômenos relativos ao pensar (no sentido de processo ou atividade, e não do pensar como ter uma crença) (e.g., refletir, calcular). Se não o faz, então falha quanto ao desiderato da abrangência; ou, se os aloca na categoria de estados qualitativos, então falha quanto à neutralidade; ou ainda, se os aloca na categoria de atitudes proposicionais, então falha quanto ao princípio da arregimentação. Alguns processos cognitivos e cogitativos são alocados pelo autor na categoria de estados qualitativos, a saber, imaginar, lembrar e diferentes formas de percepção. Porém, há perspectivas sobre fenômenos relativos ao pensar (e.g., Fodor 1975; Rachlin 1994; Turing 1950) que não sugerem se tratar de fenômenos fundamentalmente constituídos por conteúdos qualitativos. Restaria alocá-los na categoria de atitudes proposicionais. Porém, se o autor o fizesse, não os diferenciaria suficientemente de atitudes proposicionais (como crenças, intenções e expectativas), na medida em que, diferentemente delas, fenômenos como os de refletir sobre um rumo de ação e resolver um exercício de matemática são episódicos (e.g., pode-se estar resolvendo o exercício em um momento particular, fazer isso ao mesmo tempo em que se bebe água, etc.).

(iv) A taxonomia de Rey deixa de lado os traços de caráter ou de personalidade, em nenhum momento fazendo referência a eles, portanto falhando quanto à abrangência. (Vale, aqui, observação análoga a (iii) à taxonomia de McGinn).

(v) Tampouco considera habilidades, assim deixando novamente a desejar quanto à abrangência. Habilidades não satisfazem o conjunto de critérios do autor para a categoria de estados qualitativos, porquanto não são de imediata consciência (sequer fazendo sentido se falar em imediata consciência de um fenômeno que não é episódico, mas, antes, disposicional); e não estão associados a conteúdos qualitativos, não sendo experiências. A possibilidade de encaixar as habilidades na categoria de atitudes proposicionais, tal como entendida pelo autor, está igualmente excluída, na medida em que não se trata de estados designados por verbos que tenham como objetos diretos complementos da forma 'que...' ou 'de...'; e, o que é correlato dizer neste caso, não geram contextos opacos.

(vi) Os processos cognitivos e cogitativos agrupados por Rey (1997) na categoria de estados qualitativos não condizem com a terminologia de 'estados'; ou seja, o ouvir, o cheirar e outros processos perceptivos, bem como o imaginar e o lembrar, arguivelmente, não são estados. Pois estados (sejam psicológicos ou não; e.g., estar nublado, sentir cócega, estar com sede) não são fenômenos que um organismo realize, antes sendo fenômenos que lhe acontecem ou que são resultados de ações. Assim, estados, geralmente, como Kenny (2003, p.122-4) aponta, não tomam tempo, embora perdurem por um tempo (e.g., não faz sentido se dizer que estar nublado, sentir cócega e estar com sede levem tempo para ser realizados, embora leve tempo para o céu ficar nublado e um organismo ficar com cócega ou com sede). Já fenômenos como os de ver um pássaro pela janela, cheirar uma maçã, imaginar um 
pássaro comendo uma maçã, etc., tomam algum tempo. Além disso, como clarifica Kenny (2003, p.128-9), estados normalmente não admitem imperativos (e.g., normalmente não faz sentido se dizer "Esteja com cócega", "Esteja com uma tensão"). Entretanto, faz sentido, em princípio, pedir a alguém para ouvir o som de uma fonte, experimentar o gosto de uma fruta, imaginar um pássaro comendo uma maçã, lembrar-se de comer uma maçã por dia, e assim por diante.

\section{A Taxonomia de Maslin (2001)}

Maslin (2001, p.8ss) oferece uma taxonomia em termos ônticos e equivale atributos mentais a estados mentais. De modo semelhante às taxonomias de McGinn (1996) e de Rey (1997), divide-os em duas categorias gerais. Porém, ela difere dessas outras em aspectos tais como fazer um número maior de subdivisões em uma dessas categorias e distinguir outras características dos fenômenos que inclui em comum com aquelas. Eis uma representação da estrutura desta taxonomia:

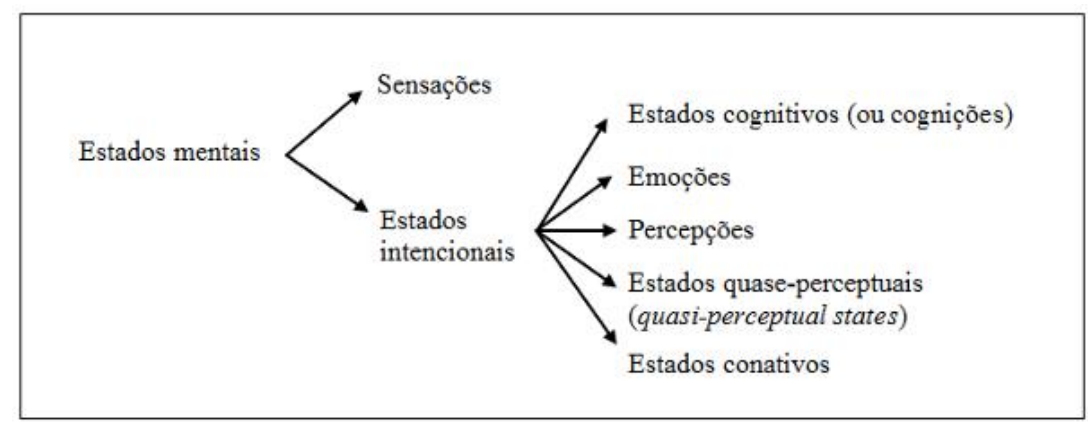

Figura 3: Estrutura da taxonomia de Maslin (2001)

Nesta classificação, os atributos mentais são divididos em sensações e estados intencionais. Sensações incluem dores, cócegas, coceiras, palpitações e assim por diante. Elas têm em comum as características de: (a) exibirem alguma forma de localização em uma ou outra parte do corpo (pois dizemos, por exemplo, que uma coceira ocorre no braço, na perna, no pé, etc.), embora não se trate de localização na mesma acepção em que um objeto ou evento comum (e.g., uma moeda, um jantar) tenham localização, pois as sensações não admitem a transitividade que um objeto ou evento comum admite (e.g., se uma moeda está no bolso e o bolso está em uma calça, então, por transitividade, a moeda está na calça; ao passo que, se uma coceira ocorre no pé e ele está em um calçado, não se segue que a coceira esteja no calçado); (b) serem ocorrências ou episódios (e não disposições); (c) envolverem consciência (awareness), no sentido de não fazer sentido se dizer que uma sensação ocorra sem que o sujeito que a exemplifica a note ocorrer; (d) exibirem fenomenolo- 
gia distintiva e constitutiva; (e) não terem intencionalidade, no sentido de sensações não serem sobre, ou dirigidas a, algo possível ou efetivo; e (f) serem fenômenos atômicos (por oposição a holísticos), isto é, que podem existir independentemente de o sujeito exemplificar ao mesmo tempo qualquer outra sensação (a existência de uma sensação individual não tem por implicação a existência simultânea de alguma outra sensação).

A categoria dos estados intencionais é subdividida por Maslin (2001) em: (1) estados cognitivos (ou cognições), exemplos dos quais ele inclui crer, saber, pensar e raciocinar; (2) emoções (em cuja categoria o autor inclui humores), como medo, vergonha, inveja, raiva, tristeza, alegria, etc.; (3) percepções, como ver, ouvir e cheirar; (4) quase-percepções, incluindo imaginar, sonhar e alucinar; e (5) estados conativos, exemplos dos quais, segundo o autor, são querer, tencionar, agir (acting) e tentar (trying). Os estados intencionais, independentemente das subcategorias em que se encaixam, apresentam, conforme esta taxonomia, as seguintes características: (a) possuem intencionalidade (isto é, a propriedade de ser sobre, ou dirigido a, algo efetivo ou possível); (b) não têm localização em alguma parte do corpo (não fazendo sentido dizer, por exemplo, que o medo de alguém ou sua admiração esteja, por exemplo, na cabeça, a alguns centímetros de suas orelhas); e (c) são fenômenos holísticos (por oposição a atômicos), ou seja, um estado intencional não pode existir isoladamente de outros, a existência de um implicando que haja ao mesmo tempo outros sendo exemplificados pelo organismo.

Maslin (2001) traça algumas distinções entre as subcategorias (1)-(5). Os estados cognitivos, segundo o autor, não são necessariamente conscientes e tampouco possuem fenomenologia constitutiva, embora possam envolver um ou mais conteúdos qualitativos incidentalmente (e.g., quando alguém declara achar que determinado livro é muito bem escrito, pode experienciar certos conteúdos qualitativos ao lembrar de passagens do livro, mas sua crença sobre ele pode existir perfeitamente sem esses conteúdos qualitativos). Emoções e humores são, conforme o autor, estados disposicionais e que não envolvem inteiramente consciência, mas a envolvem parcialmente, a saber, quando se os sente. Além disso, têm fenomenologia específica constitutiva, embora envolvida apenas nos sentimentos que os formam. Maslin não menciona feições particulares das percepções, mas caracteriza as quase-percepções como estados em que aparenta ao sujeito que os exemplifica estar percebendo (e.g., vendo, ouvindo) algo, quando, na verdade, não o está. Com relação aos estados conativos, aponta que não são necessariamente conscientes e, além disso, que alguns deles, como os de desejo, têm fenomenologia associada; porém, fala isso muito brevemente (cf. Maslin 2001, p.12), não ficando claro se considera que se trata de fenomenologia específica constitutiva (isto é, haver, por exemplo, um conteúdo qualitativo distintivo e sine qua non de desejo de passear por entre as árvores coloridas de um campus). 


\section{Ponderações à Taxonomia de Maslin (2001)}

A taxonomia ora em pauta abrange mais categorias do mental do que as taxonomias de McGinn (1996) e Rey (1997). Além disso, distingue características importantes de alguns dos fenômenos em questão não salientadas nessas outras taxonomias. Contudo, ela também requer várias ponderações. Levantamos as seguintes ponderações a ela:

(i) Esta taxonomia desconsidera os apetites, assim deixando a desejar quanto à abrangência. Os apetites não são sensações, posto que, por exemplo, diferentemente das sensações, não têm localização explícita e caráter episódico. Tampouco, arguivelmente, são emoções ou estados conativos, tendo, antes, como contrapartida, predicados monádicos (e.g., ' . . ter fome', ' ... ter sede'), e não diádicos. Além disso, não são humores, na medida em que frequentemente os humores são exprimidos empregando-se alguns predicados relativos ao dia ou ao tempo e vice-versa, como, por exemplo, quando dizemos que alguém está com um humor radiante ou nebuloso, e que o dia está alegre, triste ou sereno (cf. Ryle 1949, p.99), ao passo que isso não ocorre no caso dos apetites (e.g., não dizemos que o dia ou o tempo esteja com sede). Ademais, diferentemente de emoções e humores, os apetites muitas vezes estão associados a reações em partes típicas do corpo (e.g., certas sensações na barriga, no caso da fome).

(ii) Como as taxonomias anteriormente examinadas, a de Maslin (2001) negligencia os traços de caráter ou de personalidade. Por isso, deixa a desejar quanto à abrangência novamente.

(iii) Ou esta taxonomia oblitera habilidades, assim falhando (mais uma vez) quanto ao desiderato da abrangência; ou ela as considera, mas, alocando-as na categoria de estados cognitivos (ou cognições), deixa a desejar quanto ao princípio da arregimentação. Maslin (2001) não menciona habilidades em qualquer momento, senão apenas o saber (ou conhecer) em geral (knowing) (cf. Maslin 2001, p.8). Assim, se eventualmente incluísse habilidades em sua classificação, fá-lo-ia provavelmente na categoria de estados cognitivos (já que as habilidades são formas de saber). Porém, há diferenças bastante consensuais entre elas e os outros itens mencionados pelo autor como exemplos de estados cognitivos. Diferentemente do raciocinar, elas são atributos disposicionais, e não episódicos (e.g., um raciocínio pode começar e acabar dentro de instantes, ao passo que uma habilidade é algo que alguém pode, em princípio, ter durante praticamente uma vida inteira); e, diferentemente do crer, são coisas exercitáveis, isto é, treináveis (e.g., podemos exercitar a habilidade de falar uma língua estrangeira, mas não faz sentido se exercitar a crença de que os ipês estão belos em determinada época do ano).

(iv) Pelo princípio da arregimentação, a categoria de estados cognitivos (ou cognições), como distinguida na taxonomia de Maslin (2001), requer subdivisões. Pois 
fenômenos como os de crer e os de raciocinar diferem significativamente, a saber, em os primeiros serem disposicionais, enquanto que os segundos são episódicos.

(v) Também levando em conta o princípio da arregimentação, é recomendável subdividir a categoria de emoções e humores em pelo menos duas categorias. Pois há diferenças de nuanças básicas entre os humores (e.g., estar triste, alegre, animado, melancólico, abatido, etc.) em relação às emoções (como as de ter medo de certo animal selvagem, admirar alguém por alguma qualidade, ter prazer com uma partida de xadrez, etc.). Humores são mencionados em resposta a perguntas da forma "Como você/ele(a) está?"; e a resposta a elas, geralmente, tem a forma de um predicação em que o predicado relevante é monádico: está-se, por exemplo, sentindo um pouco ou muito alegre, triste, animado. Normalmente, essas perguntas não teriam respostas tais como "Estou admirando muito o filósofo que estávamos discutindo" ou "Estou sentindo muito prazer com essa partida de xadrez". Em outras palavras, como vários autores salientam (e.g., Lamb 1987, p.107-9; Lormand 1985, p.389; Solomon 1973, p.21; Bennett \& Hacker 2003, p.202), humores não são ligados a objetos ou eventos específicos. Falamos, aqui, em subdividir a categoria de emoções e humores presente na taxonomia ora em pauta 'em pelo menos duas categorias' porque pode-se (como alguns autores fazem; e.g., Lamb 1987; Thalberg 1964) chamar os humores de emoções, sendo recomendável que, entretanto, se distinga, nesse caso, pelo menos diferentes subcategorias de emoções.

As ponderações (vi)-(ix) a seguir dizem respeito às dimensões terminológica e intensional da taxonomia de Maslin (2001), mas sem implicar diretamente em questionamento de algum aspecto de sua estrutura.

(vi) A terminologia de 'estados intencionais', pelo menos utilizada sem qualificação, como o é na taxonomia de Maslin (2001), é problemática. Pois, conforme sustentado por vários autores, a intencionalidade - inclusive em sentido primário, e não, como sugerem alguns autores (e.g., Searle 1980), meramente de um modo derivativo - não é uma propriedade distintiva do mental. Trata-se, antes, segundo alguns autores, de uma propriedade exemplificada por fenômenos não mentais, tais como órgãos corporais e artefatos (cf., e.g., Millikan 1984, 1993), e até mesmo fenômenos disposicionais em geral, como os da solubilidade de certas substâncias e a fragilidade de certos objetos (cf. Molnar 2003; cf. também Martin \& Pfeifer 1986).

(vii) É bastante questionável considerar fenômenos tais como os de raciocinar, ver, ouvir, cheirar, agir e tentar como sendo estados. Conforme salientamos na ponderação (vi) à taxonomia de Rey (1997), estados não são coisas que um organismo faça, antes sendo coisas que lhe acontecem (ou acometem), ou que resultam de uma ação (sem serem elas mesmas ações); e, assim, não tomam tempo e, geralmente, não admitem imperativos. Por outro lado, os referidos fenômenos são coisas que um organismo, em geral, faz, e não coisas que meramente lhe acontecem. Por exemplo, levar a cabo um raciocínio em que se calcula uma multiplicação, ver e cheirar uma 
maçã, são coisas que tomam um tempo para se realizar e que podemos pedir para alguém fazer.

(viii) A ideia de que emoções e humores têm fenomenologia constitutiva, mesmo que concebida como sendo parcialmente - a saber, como sendo presente nos sentimentos que compõem (não exclusivamente) as emoções -, é problemática. Como salientamos na ponderação (i) à taxonomia de McGinn (1996), está longe de ser claro que certas emoções, como, por exemplo, o admirar alguém por possuir certa virtude e o ter satisfação com a leitura de certo texto, bem como certos humores, como, por exemplo, o de estar tranquilo, exibam qualquer fenomenologia constitutiva. Logo, pelo princípio da neutralidade, é recomendável não caracterizar, em contextos (RN), as emoções e os humores em geral como tendo, mesmo que parcialmente, fenomenologia constitutiva.

(ix) A ideia de que as emoções em geral sejam conscientes, mesmo que parcialmente - a saber, quando dizemos que a sentimos —, é problemática. O fato de alguém sentir certas reações envolvidas em uma emoção (e.g., sentir algo desagradável estando com medo ou raiva de algo) não implica que esteja simultaneamente consciente dessa emoção. Pois as pessoas, mesmo no momento em que têm essas reações, frequentemente ficam em dúvida sobre quais são as emoções que estão exemplificando. Inclusive, às vezes identificam-nas equivocadamente (cf., e.g., Bedford 1957, p.284-5; Ryle 1949, p.162). Em outras palavras, Maslin parece confundir ter consciência de uma emoção com experienciar um sentimento envolvido em uma emoção. Levando em conta o princípio da neutralidade, é recomendável não comprometer a caracterização das emoções com a referida ideia, em contextos (RN). ${ }^{11}$

\section{Uma Taxonomia Alternativa}

As taxonomias do mental das quais vários livros de introdução à filosofia da mente partem têm, como vimos, múltiplas limitações, o que constitui um motivo principal para nossa proposta de uma taxonomia alternativa, para o mesmo tipo de contexto. Sugerimos que essa alternativa (em grande parte baseada em nossa argumentação precedente), é mais abrangente, neutra e efetivamente taxonômica do que aquelas anteriormente avaliadas.

Antes de apresentarmos essa taxonomia, salientamos algumas qualificações. Em primeiro lugar, ela pode ser entendida como sendo, ao mesmo tempo, de predicados e de fenômenos (ou atributos) mentais, apesar de, por economia de palavras, apresentarmo-la, a seguir, em termos de fenômenos mentais. Em segundo lugar, o fato de apresentarmo-la assim não implica que sua adoção envolva de antemão comprometimento com algum realismo sobre as categorias distinguidas. Pode-se ter, eventualmente, uma perspectiva não realista a respeito de uma ou mais delas - 
como é o caso, por exemplo, de diferentes variantes de eliminativismo em filosofia da mente (e.g., Churchland 1988; Rorty 1965) —, mas, simultaneamente, se reconhecer que sejam classes de predicados mentais ou de pretensos fenômenos mentais. Em terceiro lugar, seguindo o princípio da abrangência, a taxonomia proposta não é fechada à possibilidade de haver categorias mentais para além daquelas que distingue, pois pode haver categorias mentais que comumente não são reputadas como tais. Em quarto lugar, ela não só pode ser aprimorada — julgamos que, em particular, pelo avanço em certos aspectos terminológicos e pela indicação de ainda mais feições das categorias (e subcategorias) distinguidas —, mas também é desejável que o seja. Em quinto lugar, embora sugerimos que se trate de uma melhor taxonomia do que aquelas outras, não deve ser entendida como tendo o intuito de ser $a$ taxonomia para esse tipo de contexto, sendo, antes, apenas uma (mais) plausível, o que o próprio fato de poder receber aprimoramentos indica.

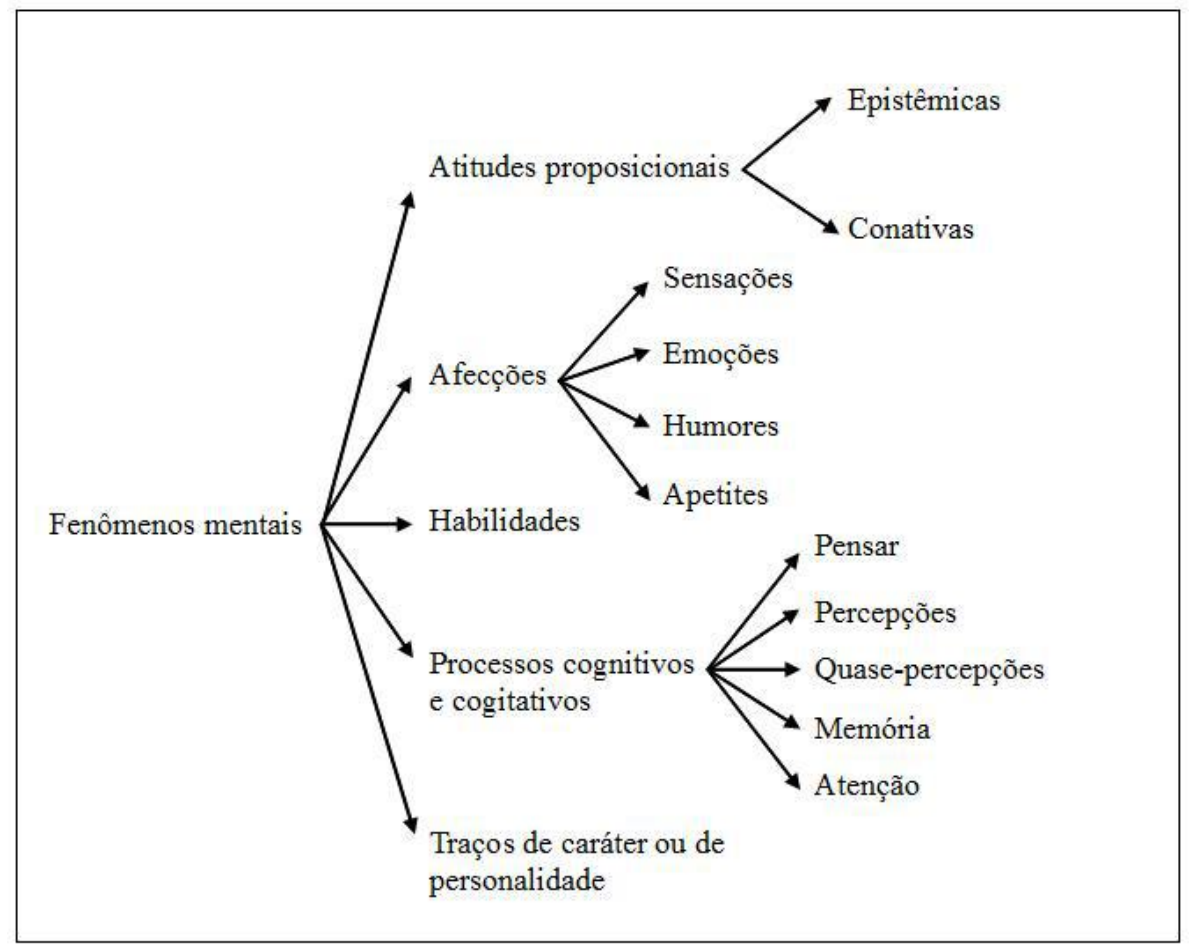

Figura 4: Uma taxonomia alternativa

Na taxonomia que propomos (cf. Figura 4), há pelo menos cinco categorias gerais: (1) atitudes proposicionais; (2) afecções; (3) habilidades; (4) processos (ou atividades) cognitivos e cogitativos; e (5) traços de caráter ou de personalidade. Subdividimos (em termos similares aos de Rey 1997) as atitudes proposicionais em 
epistêmicas e conativas. As epistêmicas representam o mundo como sendo de determinado modo ao invés de outro; por exemplo, achar que há, na segunda-feira à tarde, uma reunião do grupo de que se faz parte. Já as conativas motivam o agente com respeito a uma maneira particular como o mundo pode estar; por exemplo, querer participar de reuniões do grupo de estudos do qual se faz parte. Essas categorias não são exclusivas (não são como pigeonholes), ou seja, uma atitude proposicional pode ser tanto epistêmica como conativa; por exemplo, esperar que o fato de a reunião estar marcada para segunda-feira não lhe impeça de participar dela. Características comuns às atitudes proposicionais incluem tenderem a: (a) possuir um caráter disposicional (por oposição a episódico); (b) poder ser inconscientes (isto é, o sujeito que as exemplifica pode não saber que o faz); (c) não possuir fenomenologia constitutiva; (d) ser atribuídas em predicações que não estão estritamente conformes à lei de substituição de idênticos de Leibniz; (e) ser atributos cuja exemplificação implica a de, ao mesmo tempo, outros da mesma categoria (e.g., se alguém quer participar, na sexta-feira, da reunião do grupo do qual faz parte, então acredita que vai haver reunião do grupo nesse dia e que dele é um membro); e (f) não ter localização, pelo menos explícita, em partes do corpo, sendo, antes, propriedades do sujeito como um todo.

Empregamos a terminologia de 'atitudes proposicionais', nesta classificação, apenas por não dispormos ainda de uma terminologia mais adequada. Ela conota uma interpretação dos itens de sua extensão em termos de atitudes com respeito a proposições, mas nossa taxonomia é neutra com respeito a tal entendimento deles. Por isso, seria desejável dispormos de uma terminologia melhor para esses itens.

As afecções são subdivididas em: (2.1) sensações (e.g., cócega, coceira, dor); (2.2) emoções (e.g., estar com medo, raiva ou ciúme; admirar, amar); (2.3) humores (e.g., estar tranquilo, relaxado, alegre, animado, melancólico); e (2.4) apetites (e.g., fome, sede, concupiscência). Dentre as características desses atributos, estão as de: (a) serem estados; (b) terem conexão (conceitual) com inferências da forma '...s sente...' (e.g., sentir dor, medo, contentamento, sede) ou '... sente-se...' (e.g., sentir-se irritado, satisfeito, animado); e (c) frequentemente estarem associados a certas respostas ditas involuntárias ou passivas do organismo (se como causas dessas respostas ou, antes, sendo constituídos por elas, há controversa), tais como aumento ou diminuição do batimento cardíaco e da respiração, palidez, enrubescimento, suor, expressões faciais como sorrisos e franzimentos, alterações na tonalidades da voz, arrepios, tremores do corpo, contorções, gemidos e suspiros. As sensações distinguemse das outras afecções em pelo menos duas características, a saber, tenderem a: ter um caráter episódico; e a ter alguma forma de localização no corpo (e.g., cabeça, braço, pé), ainda que não se trate de localização no mesmo sentido dos objetos ou eventos comuns, não admitindo a transitividade destes (e.g., se um almoço ocorre na cozinha e se a cozinha está na casa de Hilary, então o almoço se passa na casa 
de Hilary; ao passo que, se uma coceira está em um dedo da mão esquerda e a mão esquerda está em um bolso, a coceira não está no bolso). Além disso, as sensações são bons candidatos a atributos que possuem fenomenologia específica constitutiva (isto é, a atributos que possuem fenomenologia distinta e que formam uma condição necessária de sua exemplificação). As emoções possuem caráter disposicional; são relações com objetos ou eventos específicos; estão (conceitualmente) ligadas a inferências de crenças (e.g., se alguém está com medo de um inseto, então acha que ele faça certas coisas perigosas); e não obedecem estritamente a lei de substituição de idênticos de Leibniz (e.g., alguém adorar a Estrela da Manhã não tem por implicação que adore a Estrela da Tarde, mesmo porque pode não saber que se trata de objetos idênticos - a saber, o planeta Vênus - e ter opiniões diferentes sobre o que descreve como 'Estrela da Manhã' em comparação com o que descreve como 'Estrela da Tarde'). Os humores têm caráter disposicional, mas não são relações com objetos ou eventos específicos. Além disso, costuma-se exprimi-los por meio de predicados relativos ao dia ou ao tempo e vice-versa (e.g., estar com um humor radiante, nebuloso, taciturno; o dia estar alegre, triste, tranquilo). Os apetites, tal como os humores, possuem caráter disposicional e não são relações com objetos específicos. Entretanto, diferentemente dos humores: não exprimimos os apetites por meio de predicados relativos ao dia ou ao tempo e vice-versa; frequentemente estão associados a reações em partes típicas do corpo (e.g., a fome frequentemente envolve sensações na barriga; a sede frequentemente envolve sensações na garganta e na boca); e têm ligação com inferências de desejos (e.g., no caso da sede, desejo de beber líquido saciador).

As habilidades (e.g., saber cozinhar determinado alimento, construir certo artefato, jogar certo jogo, falar uma língua, tocar um instrumento musical) incluem como características: (a) serem formas de conhecimento ou saber prático (isto é, de como fazer determinado tipo de coisa); (b) serem atributos que, em princípio, podem ser treinados; (c) possuem gradações, podendo-se saber pouco, razoavelmente ou bem (isto é, muito) fazer determinado tipo de coisa; (d) terem caráter disposicional; (e) possuírem, normalmente, um caráter amplamente molar, no sentido de molaridade temporal, isto é, tendem a perdurar por um tempo relativamente longo (em comparação com outros atributos mentais) (às vezes perduram praticamente uma vida inteira); (f) não possuir fenomenologia constitutiva; e (g) não terem localização explícita em alguma parte do corpo.

A categoria de processos (ou atividades) cognitivos e cogitativos engloba pelo menos as seguintes subcategorias: (4.1) atividades de pensar (que diferem do pensar na acepção de crença); (4.2) fenômenos perceptuais; (4.3) as quase-percepções, incluindo o imaginar, o sonhar e o alucinar; (4.4) fenômenos relativos à memória; e (4.5) aqueles relativos à atenção. Dizemos 'pelo menos', aqui, porquanto não temos a pretensão de indicar todas as formas de processos cognitivos e cogitativos. Similaridades de família desses fenômenos incluem tenderem a: (a) possuir um ca- 
ráter episódico; (b) não ser estados, mas atividades; (c) não ter localização explícita em alguma parte do corpo; (d) ser relações com eventos ou objetos particulares; e (e) não seguir de modo estrito a lei da substituição de idêntico de Leibniz (e.g., alguém pode lembrar que Ottawa é a capital do Canadá, sem lembrar que a atual segunda maior cidade da província de Ontário seja a capital do país). A subcategoria do pensar envolve, inter alia, processos de raciocínio e reflexão, como, por exemplo, refletir sobre o significado e a plausibilidade de enunciados, refletir sobre como fazer determinada coisa (e.g., como informar algo a alguém), fazer refletidamente deduções, induções, abduções e analogias. Nessa medida, trata-se de exercícios de certas habilidades (e.g., habilidades inferenciais e argumentativas). Os processos de percepção (e.g., ver, ouvir, cheirar) são intrinsecamente ligados aos órgãos dos sentidos (e.g., olhos, nariz, focinho, papilas gustatórias) e são relações com objetos ou eventos específicos dos arredores do sujeito (ou seja, com estímulos exteroceptivos), os quais efetivamente se dão, isto é, não são meramente possíveis (e.g., se alguém toca em uma maçã, então a maçã efetivamente é objeto do ato de tocar; do contrário, não há um real ato de tocar uma maçã, mas apenas uma quase-percepção). As quase-percepções, que são atividades eminentemente cogitativas, são aqueles fenômenos em que parece ao sujeito que os exemplifica que ele está percebendo, quando, na verdade, é apenas como se o estivesse (e.g., no imaginar neve caindo, é apenas como se estivesse percebendo neve caindo). Dizemos que os objetos de alguns (particulares) deles, como, por exemplo, de alguns sonhos e imaginações, são fantasias; nomeadamente, quando dizem respeito a eventos ou objetos fictícios, improváveis e similares. Fenômenos relacionados à memória são aqueles como os de lembrar, recordar ou memorizar que algo é ou era o caso, ou de uma experiência passada, ou ainda de como fazer algo. Os relativos à atenção (e.g., estar atento, atentar), tal como as percepções, são relações com eventos ou objetos particulares que, em geral, efetivamente se dão (e.g., não faria sentido se dizer que um organismo esteja prestando atenção em uma planta, mas não haja uma planta diante dele). Diferentemente das percepções, podem envolver relação não só com estímulos exteroceptivos (e.g., árvores, pássaros), mas também com proprioceptivos e interoceptivos (e.g., pode-se prestar atenção em palpitações no estômago e contrações musculares). Além disso, eles envolvem, em alguns casos, percepções e alguns outros fenômenos da categoria (4) (e.g., pode-se ver com atenção uma planta, refletir com maior ou menor grau de atenção sobre algo).

A terminologia de 'processos cognitivos e cogitativos' é utilizada, aqui, com qualificações. A expressão 'processo cognitivo' pode conotar os usos dela feitos em ciência cognitiva, em que, geralmente, os mencionados fenômenos são entendidos como processos de informação (ainda que haja divergências sobre pormenores importantes, inclusive sobre a própria noção de informação) (cf., e.g., Bermúdez 2010; Rowlands, 2010). Adotando o princípio da neutralidade, convém apresentar de modo 
neutro a categoria em questão com respeito a essa perspectiva, em contextos (RN). Além disso, a expressão 'processo cognitivo' é às vezes utilizada para se denominar também fenômenos que não estamos considerando como sendo da categoria (4), como, por exemplo, crenças e a habilidade de falar uma língua. Nosso emprego da expressão está conforme, em extensão, apenas a alguns autores (e.g., Rowlands 2003, 2010). Salientamos ainda que, embora o termo 'processos' possa conotar, aqui, processos que acompanhem, paralelamente, comportamentos do organismo no interior do corpo, levando em conta o princípio da neutralidade deixamos em aberto se, antes, são, de alguma forma, constituídos por processos comportamentais. Por fim, há neutralidade também, por razão similar, quanto à possibilidade de que conceitos envolvidos nessas subcategorias tenham não só, fundamentalmente, a função de reportar a certas atividades efetivas, mas também a de negar que algumas outras ocorram (e.g., quando dizemos que um organismo está prestando atenção em uma presa, estarmos, em parte, inferindo que ele não está alocando seu tempo com atividades desconexas à sua obtenção) (cf., e.g., Ryle 1949).

Os traços de caráter ou de personalidade (e.g., ser vaidoso, raivoso, alegre, organizado, corajoso, extrovertido, introvertido) são atributos que: (a) não acometem um sujeito e tampouco são realizados por ele, antes sendo coisas que um sujeito é, embora, em geral, ele tenha vindo a tornar-se assim e possa, pelo menos em princípio, deixar de sê-lo; (b) não são relações com objetos ou fatos particulares; (c) têm caráter disposicional; $(\mathrm{d})$ tendem a perdurar por um tempo relativamente longo (em comparação com outros atributos mentais); (e) frequentemente são objeto de apreciação moral, ou seja, vários deles (e.g., ser corajoso, empenhado, vaidoso, irritadiço) admitem alguns predicados morais, como '... ser uma virtude' e '. . ser um vício'; (f) não possuem fenomenologia específica constitutiva; e ( $g$ ) não possuem localização explícita no interior no corpo.

\section{Conclusão}

Há pelo menos dois tipos de contextos de taxonomias do mental: os contextos teóricos ou (T), em que a taxonomia é feita com base em respostas que uma abordagem particular dá a questões substanciais sobre os predicados ou atributos mentais; e os contextos que requerem neutralidade sobre essas questões, ou contextos (RN), como é comum a vários livros e cursos de introdução à filosofia da mente.

Sugerimos que uma taxonomia do mental, para contextos (RN), têm pelo menos três importantes desideratos: ser abrangente, neutra e efetivamente taxonômica. A não satisfação deles pode, por exemplo, fazer com que se apresente de maneira enviesada uma abordagem e se cometa petições de princípio.

Várias taxonomias do mental feitas em contextos (RN) relevam-se demasiado limitadas, falhando quanto a um ou mais desses desideratos. Neste trabalho, exa- 
minamos, em particular, aquelas de McGinn (1996), Rey (1996) e Maslin (2001), mostrando suas limitações.

Uma taxonomia alternativa foi aqui esboçada, para o mesmo tipo de contexto, à luz de três princípios inicialmente estabelecidos e correspondentes a cada um daqueles desideratos. Trata-se de uma taxonomia mais abrangente, neutra e efetivamente taxonômica do que as taxonomias que examinamos. Nessa medida, é mais vantajosa do que essas outras, embora não seja a única taxonomia plausível e, além disso, possa receber mais aprimoramentos. ${ }^{12}$

\section{Referências}

Armstrong, D. M. 1968. A Materialist Theory of the Mind. London: Routledge.

- 1984. Consciousness and Causality. In: D. M. Armstrong; N. Malcolm, Consciousness and Causality: A Debate on the Nature of Mind. Oxford: Blackwell, p.103-91.

Austin, J. L. 1962. Sense and Sensibilia. Ed. by G. J. Warnock. Oxford: Oxford University Press.

Bedford, E. 1957. Emotions. Proceedings of the Aristotelian Society, New Series, 57: 281-304.

Bennett, M. R. \& Hacker, P. M. 2003. Philosophical Foundations of Neuroscience. Oxford: Blackwell.

Bermúdez, J. L. 2010. Cognitive Science: An Introduction to the Science of the Mind. Cambridge, UK: Cambridge University Press.

Braddon-Mitchell, D. \& Jackson, F. 2007 [1996]. Philosophy of Mind and Cognition: An Introduction. $2^{\text {nd }}$ ed. Oxford: Blackwell.

Brandt, R. B. 1970. Traits of Character: A Conceptual Analysis. American Philosophical Quarterly 7(1): 23-37.

Chalmers, D. J. 1995. Facing Up to the Problem of Consciousness. Journal of Consciousness Studies 2(3): 200-19.

Churchland, P. M. 1988 [1984]. Matter and Consciousness: A Contemporary Introduction to the Philosophy of Mind. $2^{\text {nd }}$ ed. Cambridge, MA: MIT Press.

Davidson, D. 2001. Subjective, Intersubjective, Objective. Oxford: Oxford University Press.

de Sousa, R. 1994. Emotion. In: Guttenplan, S. (ed.). A Companion to the Philosophy of Mind. Cambridge, MA: MIT Press, p.270-76.

Dennett, D. 1987. The Intentional Stance. Cambridge, Mass.: MIT Press.

Fodor, J. A. 1975. The Language of Thought. New York: Crowell.

Glock, H. J. 2001. Intentionality and Language. Language \& Communication 21(2): 105-18.

Harman, G. 1990. The Intrinsic Quality of Experience. Philosophical Perspectives 4: 31-52.

Heil, J. 2004 [1998]. Philosophy of Mind: A Contemporary Introduction. $2^{\text {nd }}$ ed. London: Routledge.

Kenny, A. 2003 [1963]. Action, Emotion and Will. London: Routledge.

Kim, J. 1996. Philosophy of Mind. Boulder, CO: Westview Press.

Lamb, R. 1987. Objectless Emotions. Philosophy and Phenomenological Research 48(1): 10717.

Lewis, D. K. 1972. Psychophysical and Theoretical Identifications. Australasian Journal of Philosophy 50(3): 249-58.

Principia 16(3): 365-392 (2012). 
Lormand, E. 1985. Toward a Theory of Moods. Philosophical Studies 47(3): 385-407.

Martin, C. B. \& Pfeifer, K. 1986. Intentionality and the Non-Psychological. Philosophy and Phenomenological Research 46(4): 531-54.

Maslin, K. T. 2001. An Introduction to the Philosophy of Mind. Oxford: Polity.

McGinn, C. 1996 [1982]. The Character of Mind: An Introduction to the Philosophy of Mind. $2^{\text {nd }}$ ed. Oxford: Oxford University Press.

Millikan, R. G. 1984. Language, Thought, and other Biological Categories: New Foundations for Realism. Cambridge, MA: MIT Press.

- 1993. White Queen Psychology and Other Essays for Alice. Cambridge, MA: MIT Press.

Molnar, G. 2003. Powers: A Study in Metaphysics. Oxford: Oxford University Press.

Montague, M. 2007. Against Propositionalism. Noûs 41(3): 503-18.

Nagel, T. 1974. What is it Like to be a Bat? Philosophical Review 83(4): 435-50.

Putnam, H. 1975a [1964]. Robots: Machines or Artificially Created Life? In: Putnam, H. Mind, Language, and Reality: Philosophical Papers, Vol. 2. Cambridge: Cambridge University Press, p.386-407.

_ 1975b [1967]. The Mental Life of some Machines. In: Putnam, H. Mind, Language, and Reality: Philosophical Papers, Vol. 2. Cambridge: Cambridge University Press, p.40828.

Quine, W. V. O. 1960. Word and Object. Cambridge, MA: MIT Press.

- 1961 [1951]. Two Dogmas of Empiricism. In: Quine, W. V. O. From a Logical Point of View: Nine Logico-Philosophical Essays. $2^{\text {nd }}$ ed. New York: Harvard University Press, p.20-46.

Rachlin, H. 1994. Behavior and Mind: The Roots of Modern Psychology. New York: Oxford University Press.

Rey, G. 1997. Contemporary Philosophy of Mind: A Contentiously Classical Approach. Malden, MA: Blackwell.

Rorty, R. 1965. Mind-Body Identity, Privacy, and Categories. Review of Metaphysics 19(1): 24-54.

Rowlands, M. 2003. Externalism: Putting Mind and World Back Together Again. Montreal: McGill Queen's University Press.

- 2010. The New Science of the Mind: From Extended Mind to Embodied Phenomenology. Cambridge, MA: MIT Press.

Ryle, G. 1949. The Concept of Mind. London: Hutchinson.

Sartwell, C. 1995. Radical Externalism concerning Experience. Philosophical Studies 78: 5570.

Searle, J. 1980. Minds, Brains, and Programs. Behavioral and Brain Sciences 3(3): 417-57.

Solomon, R. C. 1973. Emotions and Choice. Review of Metaphysics 27(1): 20-41.

- 1977. The Logic of Emotion. Noûs 11(1): 41-49.

Sterelny, K. 1990. The Representational Theory of the Mind: An Introduction. Oxford: Blackwell.

Thalberg, I. 1964. Emotion and Thought. American Philosophical Quarterly 1(1): 45-55.

Turing, A. M. 1950. Computer Machinery and Intelligence. Mind 59(236): 433-60.

Tye, M. 1995. Ten Problems of Consciousness: A Representational Theory of the Phenomenal Mind. Cambridge, MA: MIT Press.

Principia 16(3): 365-392 (2012). 
Wittgenstein, L. 1953. Philosophical Investigations. Ed. by G. E. Anscombe \& R. Rhees; trans. by G. E. Anscombe. Oxford: Blackwell.

FILIPE LAZZERI

Universidade de São Paulo

Departamento de Filosofia

Faculdade de Filosofia, Letras e Ciências Humanas

filipelazzeri@gmail.com

Resumo. Os predicados psicológicos (ou mentais) ordinários e os fenômenos aos quais nos remetemos através deles podem ser agrupados em diferentes categorias. Por exemplo, costuma-se agrupar fenômenos tais como os de crença e expectativa em uma categoria de "atitudes proposicionais", enquanto que sensações, como as de dor e coceira, em uma categoria distinta. Qual seria uma taxonomia do mental plausível para se adotar em contextos como o de um livro de introdução à filosofia da mente, isto é, quando se deseja partir de pressupostos apenas mínimos sobre as características desses predicados e fenômenos? Este artigo (1) sugere alguns desideratos e princípios para tal taxonomia; (2) expõe e examina criticamente alguns casos de taxonomias feitas em livros de introdução à filosofia da mente; e (3) propõe o esboço de uma taxonomia alternativa (para o mesmo tipo de contexto).

Palavras-chave: Categorias psicológicas; taxonomia do mental; filosofia da mente.

\section{Notas}

${ }^{1}$ Utilizamos a expressão 'fenômeno', neste trabalho, como sinônimo de 'atributo', podendo, assim, englobar estados, processos, eventos e qualquer outra forma geral de atributo.

${ }^{2}$ Isso a não ser que o trabalho parta (como, e.g., o de Sterelny 1990) de um marco teórico (e.g., uma visão representacionista do mental ou de parcela do mental). Neste caso, tem por objetivo introduzir o leitor a, ou tratar de um, subconjunto próprio dessas questões, já pressupondo respostas ou posicionamentos (e.g., que excluam perspectivas inconsistentes com o marco adotado) com respeito a algumas das questões substanciais, tendo como foco questões mais restringidas (e.g., sobre como modelar mais exatamente, em termos representacionistas, determinada categoria do mental).

${ }^{3}$ Neste trabalho, as expressões 'mental' e 'psicológico' são tomadas como sinônimas.

${ }^{4}$ Ademais, a adoção deste princípio pode ser útil, ao mesmo tempo, como apresentação de alguns subproblemas envolvidos na problemática geral.

${ }^{5}$ Dizemos 'pelo menos geralmente' porque o sentir frio e o sentir calor podem ser considerados formas de sensação, mas sem que tenham sempre a referida característica.

${ }^{6}$ A expressão 'localização explícita', aqui, procura indicar que, apesar de a semântica dos conceitos para emoções, em seu uso ordinário, não ser coerente com uma concepção delas como tendo localização no interior do corpo, pode-se, em um contexto (T), propor que emoções tenham alguma forma de localização desse tipo. Isso envolveria uma revisão conceitual, a qual pode ou não ser plausível (e bem ou mal motivada). Observação análoga vale para outros casos da expressão 'localização explícita' neste trabalho.

${ }^{7}$ Os exemplos que damos na seção 2 , ao expor não só esta, mas também as outras taxonomias, são de seus próprios autores ou baseados nelas.

Principia 16(3): 365-392 (2012). 
${ }^{8}$ Utilizamos, neste trabalho, as terminologias de 'atitudes proposicionais' e 'processos cognitivos e cogitativos' para nos referirmos, respectivamente, ao reputado grupo de fenômenos tais como os de ter uma opinião, querer e tencionar, e ao reputado grupo daqueles tais como os de raciocinar, lembrar, imaginar e perceber. Porém, nós o fazemos apenas por falta de terminologias melhores. Procurando estar em conformidade com o desiderato da neutralidade, não pressupomos as interpretações dos primeiros em termos de atitudes com respeito a proposições; e tampouco as interpretações dos últimos com base em programas de pesquisa em ciência cognitiva, as quais geralmente são baseadas em noções como as de processamento de informação (cf., e.g., Bermúdez 2010; Rowlands, 2010). Falamos mais sobre essas qualificações na seção 3 .

${ }_{9}^{9}$ McGinn, em determinado momento de seu livro (cf. McGinn 1996, p.127-28), menciona mais uma suposta categoria do mental, a saber, a de tentar (trying). Porém, trata-se de um acréscimo já no âmbito de um contexto (T), isto é, de uma teorização específica que desenvolve, e não de um acréscimo à classificação inicial do livro. Entretanto, registramos, aqui, uma ponderação paralela a esse elemento ('paralela' porque diz respeito a uma classificação para outro tipo de contexto que o de interesse desse nosso presente trabalho). O tentar, segundo McGinn, não é uma sensação, porque, diferentemente das sensações, não tem uma fenomenologia característica. Tampouco, segundo o autor, é uma atitude proposicional, por, segundo ele, não envolver necessariamente racionalidade (que o autor relaciona à capacidade de raciocinar), já que um animal não humano pode tentar fazer coisas, sem que seja racional (sob o critério de racionalidade do autor); e atribuímos o tentar na forma de 'tentar algo', e não de 'tentar que'. O tentar seria, assim, uma terceira categoria geral. Esta classificação do fenômeno do tentar é bastante problemática, pois, por exemplo, é baseada na ideia de que as atribuições de atitudes proposicionais sempre se dão com complementos frasais da forma 'que...' (o que não significa dever ele ser considero como atitude proposicional).

${ }^{10}$ Como é sabido, essa lei diz que a substituição de uma expressão, em um enunciado declarativo, por uma expressão que tenha a mesma extensão, forma um enunciado que mantém o valor de verdade do primeiro. Predicados em questão não satisfazem essa lei na medida em que, por exemplo, um enunciado como "Édipo quer bater em Laio" pode ser verdadeiro, mas ser falso "Édipo quer bater em seu pai", apesar de o termo 'Laio' estar sendo substituído por uma expressão com mesma extensão.

11 Outras taxonomias que investigamos são suscetíveis a ponderações que levantamos com relação àquelas aqui examinadas. Por exemplo, a de Kim (1996, p.13-5) é suscetível a ponderações análogas a (i) e (v) à de Maslin e a (iii) e (vii) à de McGinn. No caso da taxonomia de Kim (1996), declarando o autor não pretender generalidade, mas apenas mencionar "algumas categorias maiores" (major categories) de fenômenos mentais (cf. Kim 1996, p.13), algumas dessas ponderações não são propriamente objeções, servindo apenas para visualizarmos limitações que ela possui.

12 Agradecemos, de modo especial, a Beatriz S. Marques, Felipe S. Amaral, Herivelto P. Souza, Jéssica F. de Carvalho, Jorge M. Oliveira-Castro, Luiz Henrique de A. Dutra, Miguel Romero, Osvaldo Pessoa Jr. e Paulo C. Abrantes, pelas valiosas conversas acerca de um ou mais aspectos do trabalho. O conteúdo, porém, é de responsabilidade apenas do autor. Trabalho apoiado por bolsa de doutorado da Fundação de Amparo à Pesquisa do Estado de São Paulo (FAPESP).

Principia 16(3): 365-392 (2012). 